\title{
Impact of an integrated intervention program on atorvastatin adherence: a randomized controlled trial
}

This article was published in the following Dove Press journal:

International Journal of General Medicine

29 July 2013

Number of times this article has been viewed

\author{
Nilesh J Goswami' \\ Mitch DeKoven ${ }^{2}$ \\ Andreas Kuznik ${ }^{3}$ \\ Jack Mardekian ${ }^{3}$ \\ Michelle R Krukas ${ }^{2}$ \\ Larry Z Liü,4 \\ Patrick Bailey' \\ Cynthia Deitrick ${ }^{5}$ \\ John Vincent ${ }^{3}$
}

'Prairie Heart Cardiovascular Consultants, Springfield, IL, USA; ${ }^{2}$ Health Economics and Outcomes Research, IMS Health, Alexandria, VA, USA; ${ }^{3}$ Pfizer Inc, New York, NY, USA; 'Weill Cornell Medical College, Cornell University, New York, NY, USA; ${ }^{5}$ Prairie Heart Education and Research Cooperative, Springfield, IL, USA
Correspondence: Mitch DeKoven Health Economics and Outcomes Research, IMS Health, I725 Duke Street, Suite 510 , Alexandria, VA, USA 22314

$\mathrm{Tel}+\mathrm{I} 7038375153$

Fax +I 7038375170

Emailmdekoven@us.imshealth.com
Background: This trial evaluated the effectiveness of an integrated intervention program that included a 3-to-5-minute nurse counseling session, copay relief cards, and a monthly newsletter on adherence to atorvastatin treatment.

Methods and results: A prospective, integrated (composed of nurse counseling, adherence tip sheet, copay relief card, opportunity to enroll in 12-week cholesterol management program) randomized interventional study was designed involving patients $>21$ years of age who were prescribed atorvastatin at a large single-specialty cardiovascular physician practice in Illinois from March 2010 to May 2011. Data from the practice's electronic medical record were matched/ merged to IMS Health's longitudinal data. A total of 500 patients were enrolled (125 in the control arm; 375 in the intervention arm). After data linkage, 53 control patients and 155 intervention patients were included in the analysis.

Results: Mean age was 67.8 years (control) and 69.5 years (intervention); $67.9 \%$ and $58.7 \%$, respectively, were male. The mean 6 -month adherence rate was 0.82 in both arms. The mean proportion of days covered for both the new-user control and intervention groups was the same, averaging 0.70 day (standard deviation [SD], 0.27 day); for continuing users, the proportion of days covered for the control group was 0.83 (SD, 0.24) and for the intervention group was 0.84 (SD, 0.22). For continuing users, the control group had mean persistent days of 151.6 (SD, 50.2) compared with 150.9 days (SD, 50.9) for the intervention group. New users had fewer persistent days (control 111.4 days, SD, 69.6 days; intervention 112.0 days, SD, 58.8 days) compared with continuing users. The Cox proportional hazards model of the risk of discontinuation with index therapy was not significantly different between the intervention and control groups (hazard ratio $0.83, P=0.55$ ).

Conclusion: The integrated intervention program did not significantly improve atorvastatin adherence relative to usual care in the studied patient population.

Keywords: adherence, randomized clinical trial, atorvastatin

\section{Introduction}

Heart disease is the leading cause of death for men and women in the United States, and the predominant etiology is coronary artery disease. Atorvastatin (Lipitor ${ }^{\circledR}$, Pfizer Inc. New York, NY, USA) is a highly efficacious lipid-lowering agent that acts as a competitive inhibitor of 3-hydroxy-3-methylglutaryl-CoA-reductase. ${ }^{1}$ Primary and secondary prevention studies have shown that the use of 3-hydroxy-3-methylglutarylCoA-reductase inhibitors (statins) in patients with coronary artery disease reduces recurrent events and mortality. ${ }^{2,3}$

Atorvastatin is one of the most studied drugs with regards to clinical data, having been shown to reduce acute coronary heart disease events, coronary revascularization, 
and rate of stroke. ${ }^{4,5}$ In addition, its efficacy has been confirmed in a variety of populations. ${ }^{6-8}$ However, the beneficial effects described above may only be realized if patients take their medicines as prescribed by their health care practitioner (ie, adhere to treatment); unfortunately, adherence to these medicines is modest at best. ${ }^{9,10}$ Several studies have shown that adherence to statins decreases to $50 \%$ by 12 months after the initial prescription, ${ }^{11,12}$ although some evidence suggests that adherence to atorvastatin may be higher than it is for other statins. ${ }^{13}$ For medications across a wide range of disease areas $15 \%-20 \%$ of new prescriptions are never filled, 20\%-35\% of patients who do fill the first prescription fail to fill a second, and adherence continues to decline rapidly throughout the first 3-6 months of therapy. ${ }^{14,15}$ More specifically, statin persistence in older patients $\geq 65$ years of age, declines over time, with the greatest drop occurring in the first 6 months of treatment. ${ }^{16}$

Multiple barriers to taking medicines have been described by the World Health Organization and others, the most common being forgetfulness. Others include lack of knowledge, fear of adverse events, psychological factors, and cost. Intervention strategies that integrate counseling, emotional support, and cost sharing are motivational and have been shown to improve adherence. ${ }^{17-23}$ The objective of this study was to describe and evaluate the effectiveness of an integrated intervention program on patients' adherence to statin therapy, using atorvastatin as a specific example.

\section{Methods}

This was a randomized, prospective study that involved patients who were prescribed atorvastatin at Prairie Heart Cardiovascular Consultants, Springfield, ILL, USA, that performs diagnostic catheterization, angioplasties, implants, and heart surgeries. Ten practicing physicians (all board-certified cardiologists, some of whom are interventionalists, and others noninterventionalists) participated, on the basis of their total clinic volume and clinical research interest. Patients who met the study criteria (described below), and were prescribed atorvastatin by a participating physician after study initiation, whether they were considered new or returning practice patients, were eligible to enroll into this trial.

Eligible patients were randomized using a telephone randomization system to one of two groups: an intervention group and a control group (with a patient ratio of 3:1 intervention:control). All patients randomized to the intervention group were provided adherence counseling from a nurse(via a 5-10-minute discussion), and an adherence tip sheet. Patients in the intervention group were also given the opportunity to enroll in the My HeartWise ${ }^{\text {TM }}$ Program, ${ }^{24}$ a 12-week guide to managing cholesterol (included monthly mailing of educational materials). The practice physicians also had the discretion to provide eligible patients in the intervention group with a copay relief card (usable with commercial payers, not Medicare). The control group received usual care, with no additional adherence counseling or tip sheet.

\section{Data source}

Data for this study was sourced from the practice's electronic medical record system and was matched and merged to IMS Health's (Plymouth Meeting, PA, USA) longitudinal (LRx) data. The matching process was based upon patient name, gender, mailing address, and date of birth. This generated a de-identified database that was used for the study's analyses. The IMS LRx database covers $65 \%$ of all retail prescriptions in the United States and includes mail service and specialty pharmacy provider prescriptions. In this database, the de-identified patient, pharmacy, and prescriber can be tracked, as well as all dispensed prescriptions independent of the method of payment. Prescription records are collected directly from pharmacies, which provide encrypted patient identifiers, compliant with Health Insurance Portability and Accountability Act privacy regulations.

\section{Sample selection}

The target sample was enrolled in the study from March 2010 through May 2011. The period of analysis for each patient was 180 days from the first fill date of the index atorvastatin prescription (index date) to the end of the study. All subjects enrolled met the Lipitor physician prescribing information for atorvastatin and were entered into the trial at the physician's discretion. All subjects had to satisfy inclusion criteria to be considered eligible for participation by one of the ten participating physicians of the practice's study team: (1) be older than 21 years of age and, on the basis of clinical assessment by his or her physician, a candidate for statin therapy; (2) have received a first prescription for atorvastatin after study initiation at the practice, including patients who were new to the practice and returning practice patients (new versus continuing atorvastatin patients were deciphered by requiring claims activity 6 months before and after the index date); and (3) provide a personally signed and dated informed consent document indicating that the participant (or a legally acceptable representative) had been informed of all pertinent aspects of the study. Patients were excluded from the study if they were unwilling to participate 
in the adherence counseling or unwilling to give a written informed consent document. Ethics approval for the study was granted by Fox Commercial Institutional Review Board (Springfield, IL, USA).

\section{Statistical analysis}

Descriptive statistics were tabulated for all patient characteristics. A sample size of 500 patients, selected in order to have at least 300 evaluable patients (225 intervention patients and 75 control patients), was calculated for this study. This sample size provides at least $80 \%$ power at a Type 1 error rate of 0.05 to detect an effect size (proportion of days covered $\left.[\mathrm{PDC}]_{\text {intervention }}-\mathrm{PDC}_{\text {control }} / \mathrm{PDC}_{\text {standard deviation }}\right)$ of at least 0.37 . For continuous variables, measures of central tendency (mean and median) and measures of dispersion (standard deviation [SD]) were calculated and reported. For categorical variables, frequencies and percentages were calculated and reported.

As one of the main objectives of the study was to calculate the adherence to atorvastatin after study enrollment, both the PDC and medication possession ratio (MPR) during the 180 days from the patient's index date were used in the analysis. The PDC was calculated as the total number of days with the medication on hand during the 180 days from the index date divided by the total number of days in the study period (180). If the patient filled a prescription near the end of the study period that extended beyond the study period, the data for this patient was censored at that point. For example, if a patient filled a 30 -day prescription on day 160 , only 20 days' supply of that prescription (ie, up to day 180) was used in the numerator to calculate PDC. Mean PDC was reported overall and for the intervention and control groups. The MPR was defined as the number of days on medication after study enrollment divided by the number of days between the first fill and the last refill plus the days supply of last refill. The MPR for up to 180 days after the index date was computed:

MPR

$$
\begin{aligned}
& \sum \text { days supply of medication } \\
& =\overline{\sum \text { number of days between the first fill and the last refill }} \\
& + \text { days supply of the last refill }
\end{aligned}
$$

If the last refill in the study period provided supply that lasted beyond 180 days after the index date, the supply of that refill was truncated at day 180 postindex in calculating the MPR. Calculation of the MPR required that the patient had at least two medication fills. If the patient had evidence of only a single fill, the MPR was set to zero.
Both PDC and MPR were dichotomized into a categorical "adherent/not adherent" variable. Patients were defined as adherent if their PDC/MPR $\geq 80 \%$; all others were classified as nonadherent. The proportion of patients who met this criterion was reported overall and for the intervention and control groups. Exploratory logistic regressions were performed using the adherent or nonadherent categorization as the dependent variable (adjusted for demographic and baseline characteristics), to explore variables that were important in predicting adherence for both intervention and control patients. Parameter estimates and $P$-values were reported for each covariate modeled.

Persistence was measured as the number of days a patient was supplied with medication before experiencing a gap in medication $\geq 30$ days. Mean and median days of persistence were reported for the intervention and control groups. Persistence was compared between the control and the intervention groups using a time-to-event Cox proportional hazards model, adjusted for the same demographic and baseline characteristics used in the logistical regression analyses of PDC and MPR.

\section{Results}

The study initially included 500 patients (125 control patients and 375 patients who received the adherence intervention). After matching with the LRx database, 97 controls and 319 intervention patients remained eligible for analysis. However, only 93 controls and 300 intervention patients actually had any LRx claims available for analysis during the study window. Of this group, 57 controls and 180 intervention patients had an atorvastatin prescription after enrollment in the study, which served as the index date. After applying the study requirement of claims activity 6 months before and after the index date, only 53 controls (seven new users [first atorvastatin prescription after randomization] and 46 continuing users [evidence of atorvastatin prescription within 6 months prior to randomization]) and 155 intervention patients (14 new users and 141 continuing users) remained eligible for analysis (Figure 1).

\section{Patient demographic and clinical characteristics}

Table 1 provides the descriptive data around the baseline demographic and clinical characteristics for both the control and intervention cohorts. Among the control group, the average age was 67.8 years, compared with 69.5 years for the intervention group. Most of the control group (58.5\%) was 


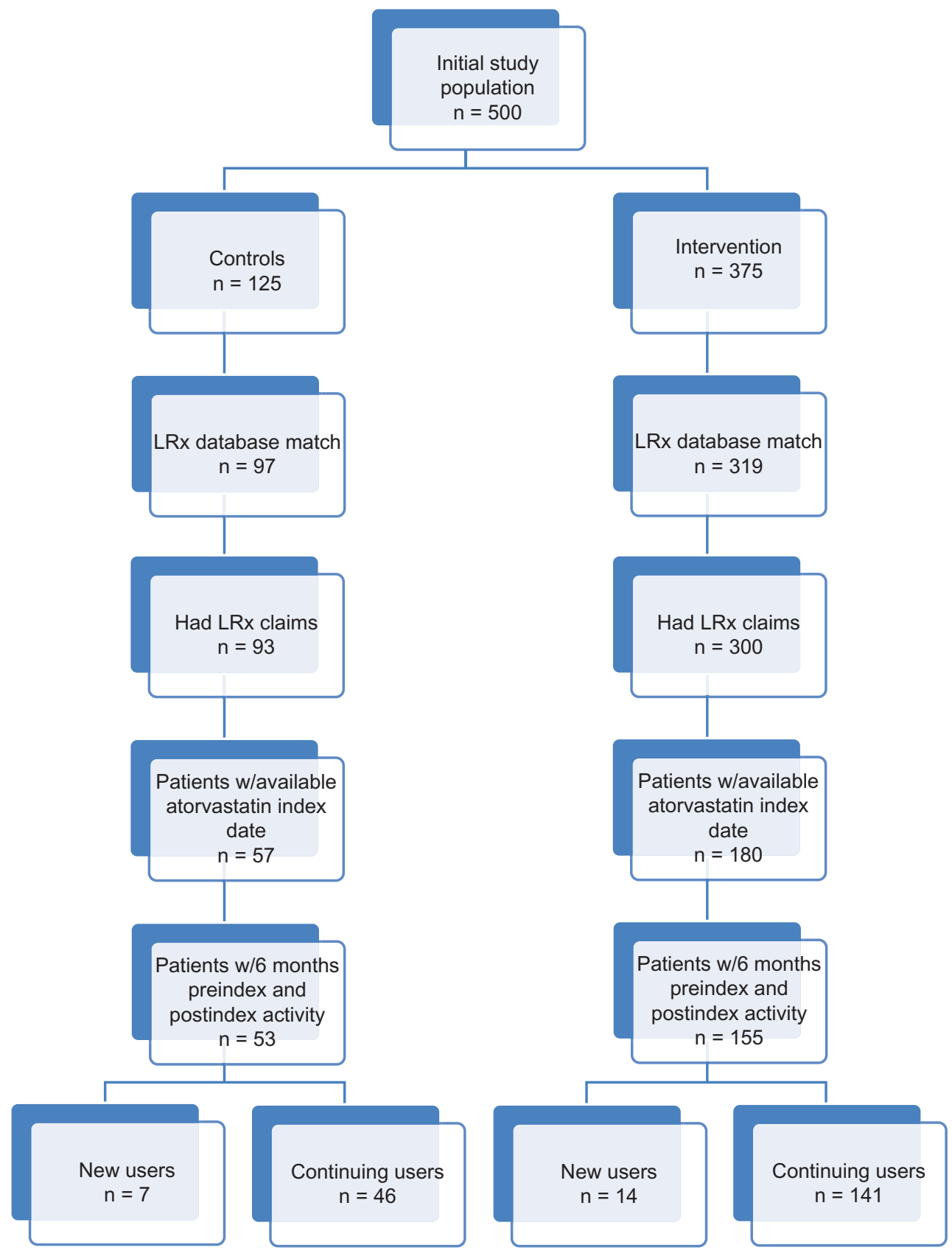

Figure I Patient disposition.

Abbreviations: $n$, number; LRx, IMS Health's longitudinal data; w/6, within 6 .

65 years of age or older; similarly, $65.2 \%$ of the intervention group was older than 65 years of age. The sex distribution was predominantly male for both groups $(67.9 \%$ of the controls and $58.7 \%$ of the intervention group). Most patients (67.9\% of the controls and $70.3 \%$ of the intervention group) were in "commercial" or "other" insurance plans.

At the index date, the control population was taking an average of 7.8 unique prescriptions, as compared to 7.1 for the intervention group. Along the same lines, the control group filled an average of 32.8 prescriptions (for any medication) in the 6 months prior to the index date, whereas the intervention group filled an average of 26.2 prescriptions. Targeted clinical characteristics for the study cohorts also are presented in Table 1. The two groups were similar with respect to their pre-enrollment clinical variables. A prior $\mathrm{CV}$ event was identified in $98.1 \%$ of the controls and $85.2 \%$ of the intervention group in the preindex period. Control patients received more antidiabetic (control 30.2\%; intervention 28.4\%) and antihypertensive (control 96.2\%; intervention $94.2 \%)$ medications compared to intervention patients. 
Table I Patient demographic and clinical characteristics

\begin{tabular}{|c|c|c|c|c|}
\hline \multirow{2}{*}{$\begin{array}{l}\text { Demographics } \\
\text { Age (years) }\end{array}$} & \multicolumn{2}{|c|}{$\begin{array}{l}\text { Control } \\
(n=53)\end{array}$} & \multicolumn{2}{|c|}{$\begin{array}{l}\text { Intervention } \\
(\mathrm{n}=155)\end{array}$} \\
\hline & & & & \\
\hline Mean & 67.8 & & 69.5 & \\
\hline SD & 10.6 & & 12.3 & \\
\hline Median & 68.0 & & 69.0 & \\
\hline \multicolumn{5}{|l|}{ Age group (n, \%) } \\
\hline $18-44$ years & 0 & $0.0 \%$ & 1 & $0.6 \%$ \\
\hline $45-54$ years & 8 & $15.1 \%$ & 15 & $9.7 \%$ \\
\hline $55-64$ years & 14 & $26.4 \%$ & 38 & $24.5 \%$ \\
\hline $65-74$ years & 16 & $30.2 \%$ & 48 & $31.0 \%$ \\
\hline $75+$ years & 15 & $28.3 \%$ & 53 & $34.2 \%$ \\
\hline Male $(n, \%)$ & 36 & $67.9 \%$ & 91 & $58.7 \%$ \\
\hline \multicolumn{5}{|l|}{ Index insurance type (n, \%) } \\
\hline Medicare & 16 & $30.2 \%$ & 44 & $28.4 \%$ \\
\hline Cash & 0 & $0.0 \%$ & 0 & $0.0 \%$ \\
\hline Medicaid & 1 & $1.9 \%$ & 2 & $1.3 \%$ \\
\hline Commercial/other & 36 & $67.9 \%$ & 109 & $70.3 \%$ \\
\hline \multicolumn{5}{|c|}{ Number of unique prescriptions at index } \\
\hline Mean & 7.8 & & 7.1 & \\
\hline SD & 3.6 & & 3.2 & \\
\hline Median & 7.0 & & 7.0 & \\
\hline \multicolumn{5}{|c|}{ Health services in the 6 months before the index date } \\
\hline \multicolumn{5}{|c|}{ Number of scripts filled (for any medication) } \\
\hline Mean & 32.8 & & 26.2 & \\
\hline SD & 23.4 & & 17.9 & \\
\hline Median & 29.0 & & 21.0 & \\
\hline $\begin{array}{l}\text { At least one fill for atorvastatin } \\
\text { (continuing patients) (n, \%) }\end{array}$ & 46 & $86.8 \%$ & $14 \mid$ & $91.0 \%$ \\
\hline \multicolumn{5}{|c|}{ Pre-enrollment clinical variables (n, \%) } \\
\hline Prior cardiovascular event & 52 & $98.1 \%$ & 132 & $85.2 \%$ \\
\hline Diabetes & 6 & $11.3 \%$ & 7 & $4.5 \%$ \\
\hline Hypertension & 42 & $79.2 \%$ & 127 & $81.9 \%$ \\
\hline \multicolumn{5}{|c|}{ Pre-index prescriptions (6 months pre-index) (n, \%) } \\
\hline Antiplatelets & 22 & $41.5 \%$ & 48 & $31.0 \%$ \\
\hline Non-statin-lowering agents & 12 & $22.6 \%$ & 31 & $20.0 \%$ \\
\hline Antidiabetics & 16 & $30.2 \%$ & 44 & $28.4 \%$ \\
\hline Antihypertensives & 51 & $96.2 \%$ & 146 & $94.2 \%$ \\
\hline Antiarrhythmics & 2 & $3.8 \%$ & 9 & $5.8 \%$ \\
\hline
\end{tabular}

Abbreviations: $n$, number; SD, standard deviation.

A history of hypertension was similar across the groups, with $79.2 \%$ of the controls having the comorbid condition as compared to $81.9 \%$ of the intervention group.

\section{Adherence}

Adherence to index therapy was measured using both PDC and MPR (Table 2), with results stratified as to whether the patient was considered a new user or a continuing user, on the basis of the presence (or absence) of atorvastatin prescriptions in the 6-month preindex period. On the basis of PDC $(\geq 0.80$ ), approximately $72 \%$ of all patients were considered adherent (76.4\% based upon MPR), with a mean PDC of 0.82 (0.81 based upon MPR). The mean PDC for the new-user control and intervention groups were similar, averaging 0.70
(SD, 0.27), whereas for continuing users, the control group exhibited a PDC of 0.83 (SD, 0.24) and the intervention group 0.84 (SD, 0.22). The mean MPR for new users within the control group was 0.58 (SD, 0.44) and was 0.62 (SD, 0.42) for new users within the intervention group. Three of the seven new users in the control group $(42.9 \%)$ were considered to have good adherence (PDC and MPR $\geq 0.80$ ) while five $(35.7 \%$ when examining PDC) and six (42.9\% when examining MPR) new users in the intervention group were considered to have good adherence. Continuing users within the control group had a mean MPR of 0.83 (SD, 0.29) as compared with 0.84 (SD, 0.28) for those in the intervention group. In general, the continuing users in both groups were considered to have good adherence, with $76.1 \%$ of the control group (when using PDC, versus $80.4 \%$ when using MPR) and $75.2 \%$ of the intervention group (when using PDC, versus $80.1 \%$ when using MPR) having PDC $>0.80$.

Figure 2A shows the overall adherence (PDC) over time of both the control and intervention groups, up to 12 months postindex. For the control group, the mean PDC decreased from an average of 0.89 ( 3 months postindex) to 0.73 ( 12 months postindex); this decline was almost exactly matched in the intervention group, going from 0.91 ( 3 months postindex) to 0.74 (12 months postindex). Not all study patients had 12 months of follow-up for this analysis, and these were censored at the end of followup (the control group had 33 patients, and 101 remained in the intervention group). Similarly, the percentage of patients who were considered to have good adherence $(\mathrm{PDC} \geq 0.80)$ decreased from $84.9 \%$ (3 months postindex) to $60.6 \%$ (12 months postindex) in the control group and from $82.6 \%$ ( 3 months postindex) to $58.4 \%$ (12 months postindex) in the intervention group (Figure 2B).

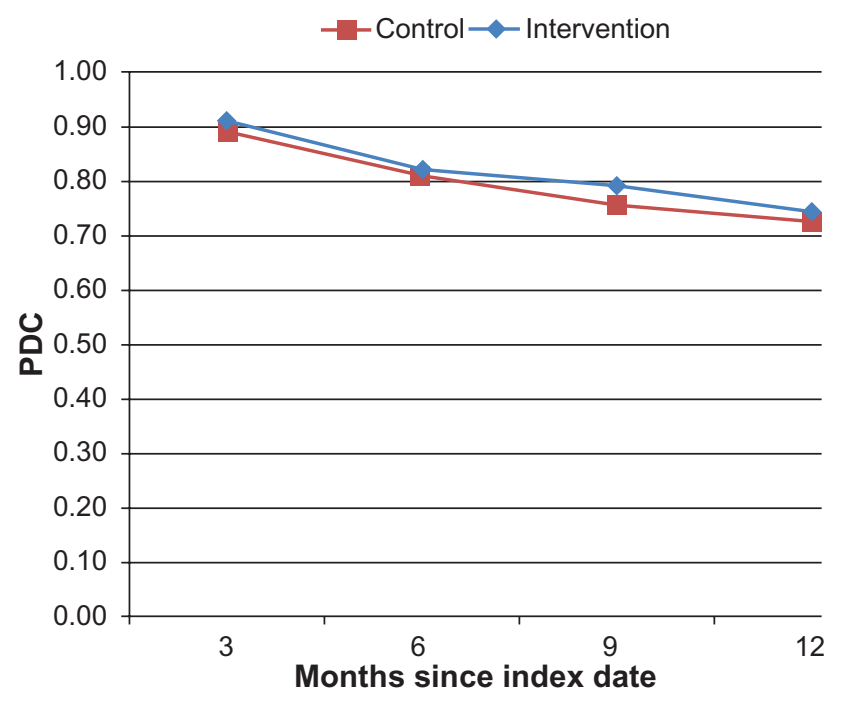

Figure 2A Mean adherence (PDC).

Abbreviation: PDC, proportion of days covered. 


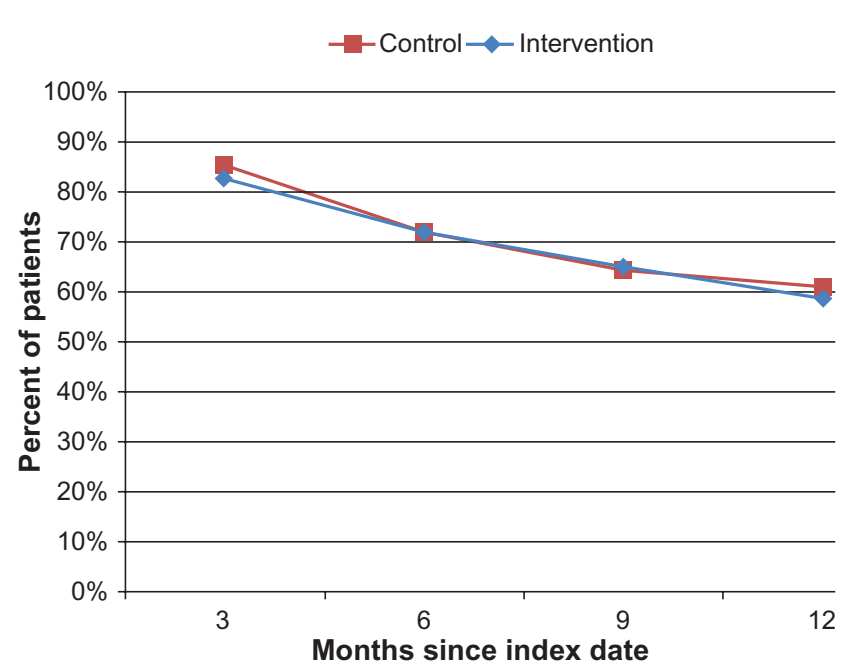

Figure 2B Percentage of patients considered adherent (PDC). Abbreviation: PDC, proportion of days covered.

After adjusting for baseline demographic and clinical characteristics, there was no significant difference in PDC with index therapy between the two patient cohorts (odds ratio $=1.03$ for intervention versus control; $P=0.95$ ) (Table 3). Patients aged 65-74 years (as compared with patients aged 18-54 years) with a prior CV event or history of hypertension were less likely to be adherent to index therapy over 6 months, whereas males, patients aged 55-64 years or $75+$ years (as compared with the patients aged 18-54 years), and patients with a history of diabetes were more likely to be adherent over the 6-month postindex period. The same logistic regression model with MPR as the dependent variable yielded similar results (odds ratio $=1.14$ for intervention versus control; $P<0.75$ ). Patients aged 65-74 years (as compared with patients aged 18-54 years) and with a history of hypertension were less likely to be adherent to index therapy over
6 months. Patients who were male, aged 55-64 years or 75+ years (as compared with patients aged 18-54 years), with a prior CV event, or with a history of diabetes were more likely to be adherent over the 6-month postindex period.

\section{Persistence}

Table 2 provides the descriptive data for persistence with the index therapy over the 6-month postindex period. Index atorvastatin patients who were deemed continuing users had more persistent days over the 6-month postindex period compared with new users. For continuing users, the control group had mean persistent days of $151.6(\mathrm{SD}, 50.2)$ compared with 150.9 (SD, 50.9) for the intervention group. The new users had fewer persistent days (control 111.4 days, SD, 69.6 days; intervention 112.0 days, $\mathrm{SD}, 58.8$ days) compared with the continuing users.

The Cox proportional hazards model of the risk of discontinuation with index therapy (Table 3 ) did not show a significant difference between the intervention and control groups after adjusting for baseline demographic and clinical characteristics (hazard ratio $0.83, P<0.55$ ). Patients aged 65-74 years (as compared with patients aged 18-54 years) or with a history of hypertension were at greater risk for discontinuing their index therapy, whereas males and patients aged 55-64 years or 75+ years (as compared with patients aged 18-54 years), with a prior CV event, or with a history of diabetes were at a lower risk of discontinuing index therapy.

\section{Discussion}

This trial was designed to evaluate the effectiveness of an integrated intervention program (nurse counseling,

Table 2 Summary of adherence measures

\begin{tabular}{|c|c|c|c|c|c|c|c|c|c|c|c|c|}
\hline \multirow{2}{*}{ PDC } & \multicolumn{4}{|c|}{ All users } & \multicolumn{4}{|c|}{ New users } & \multicolumn{4}{|c|}{ Continuing users } \\
\hline & \multicolumn{2}{|c|}{ Control } & \multicolumn{2}{|c|}{ Intervention } & \multicolumn{2}{|c|}{ Control } & \multicolumn{2}{|c|}{ Intervention } & \multicolumn{2}{|c|}{ Control } & \multicolumn{2}{|c|}{ Intervention } \\
\hline Adherent $(\geq 0.80)(n, \%)$ & 38 & $71.7 \%$ & 111 & $71.6 \%$ & 3 & $42.9 \%$ & 5 & $35.7 \%$ & 35 & $76.1 \%$ & 106 & $75.2 \%$ \\
\hline \multicolumn{13}{|l|}{ Adherence } \\
\hline Mean & 0.81 & & 0.82 & & 0.70 & & 0.70 & & 0.83 & & 0.84 & \\
\hline SD & 0.24 & & 0.23 & & 0.27 & & 0.27 & & 0.24 & & 0.22 & \\
\hline \multicolumn{13}{|l|}{ MPR } \\
\hline Adherent $(\geq 0.80)(n, \%)$ & 40 & $75.5 \%$ & 119 & $76.8 \%$ & 3 & $42.9 \%$ & 6 & $42.9 \%$ & 37 & $80.4 \%$ & 113 & $80.1 \%$ \\
\hline \multicolumn{13}{|l|}{ Adherence } \\
\hline Mean & 0.79 & & 0.82 & & 0.58 & & 0.62 & & 0.83 & & 0.84 & \\
\hline SD & 0.32 & & 0.30 & & 0.44 & & 0.42 & & 0.29 & & 0.28 & \\
\hline \multicolumn{13}{|l|}{ Persistence } \\
\hline Mean & 146.3 & & 147.4 & & 111.4 & & 112.0 & & 151.6 & & 150.9 & \\
\hline SD & 54.1 & & 52.6 & & 69.6 & & 58.8 & & 50.2 & & 50.9 & \\
\hline
\end{tabular}

Abbreviations : PDC, proportion of days covered; $n$, number; SD, standard deviation; MPR, medication possession ratio. 
Table 3 Results of multivariable regression models

\begin{tabular}{|c|c|c|c|c|c|c|c|c|c|}
\hline \multirow[t]{3}{*}{ Variable $e^{*,+, \neq}$} & \multicolumn{3}{|c|}{$\begin{array}{l}\text { PDC } \\
\text { (logistic regression) }\end{array}$} & \multicolumn{3}{|c|}{$\begin{array}{l}\text { MPR } \\
\text { (logistic regression) }\end{array}$} & \multicolumn{3}{|c|}{$\begin{array}{l}\text { Risk of discontinuation } \\
\text { (Cox proportional hazards } \\
\text { model) }\end{array}$} \\
\hline & \multirow{2}{*}{$\begin{array}{l}\text { Odds } \\
\text { ratio }\end{array}$} & \multicolumn{2}{|l|}{$95 \% \mathrm{Cl}$} & \multirow{2}{*}{$\begin{array}{l}\text { Odds } \\
\text { ratio }\end{array}$} & \multicolumn{2}{|l|}{$95 \% \mathrm{Cl}$} & \multirow{2}{*}{$\begin{array}{l}\text { Hazard } \\
\text { ratio }\end{array}$} & \multicolumn{2}{|l|}{$95 \% \mathrm{Cl}$} \\
\hline & & $\begin{array}{l}\text { Lower } \\
\text { limit }\end{array}$ & $\begin{array}{l}\text { Upper } \\
\text { limit }\end{array}$ & & $\begin{array}{l}\text { Lower } \\
\text { limit }\end{array}$ & $\begin{array}{l}\text { Upper } \\
\text { limit }\end{array}$ & & $\begin{array}{l}\text { Lower } \\
\text { limit }\end{array}$ & $\begin{array}{l}\text { Upper } \\
\text { limit } \\
\end{array}$ \\
\hline Intervention versus control & 1.03 & 0.48 & 2.21 & 1.14 & 0.51 & 0.51 & 0.83 & 0.46 & 1.52 \\
\hline Male versus female & 1.26 & 0.64 & 2.50 & 1.21 & 0.59 & 0.59 & 0.91 & 0.53 & 1.55 \\
\hline \multicolumn{10}{|l|}{ Age group } \\
\hline $55-64$ years versus I $8-54$ years $*, \dagger$ & 3.98 & 1.22 & 12.99 & 3.84 & 1.05 & 1.05 & 0.39 & 0.14 & 1.10 \\
\hline $65-74$ years versus $18-54$ years & 0.76 & 0.27 & 2.09 & 0.64 & 0.22 & 0.22 & 1.51 & 0.67 & 3.42 \\
\hline $75+$ years versus $18-54$ years & 2.44 & 0.85 & 7.03 & 1.81 & 0.60 & 0.60 & 0.73 & 0.31 & 1.72 \\
\hline \multicolumn{10}{|l|}{ Pre-enrollment comorbidities } \\
\hline $\begin{array}{l}\text { Prior cardiovascular event } \\
\text { (yes versus no) }\end{array}$ & 0.91 & 0.28 & 2.92 & 1.16 & 0.36 & 0.36 & 0.77 & 0.31 & 1.88 \\
\hline Hypertension (yes versus no) ${ }^{*,+. \neq}$ & 0.20 & 0.06 & 0.63 & 0.26 & 0.08 & 0.08 & 3.19 & 1.24 & 8.19 \\
\hline Diabetes (yes versus no) & 1.45 & 0.34 & 6.23 & 1.04 & 0.24 & 0.24 & 0.66 & 0.20 & 2.22 \\
\hline $\begin{array}{l}\text { Number of unique medications } \\
\text { at index (log of) }\end{array}$ & 0.93 & 0.48 & 1.83 & 1.12 & 0.56 & 0.56 & 1.14 & 0.67 & 1.92 \\
\hline
\end{tabular}

Notes: *Statistically significant variable for PDC model; †statistically significant variable for MPR model; *statistically significant variable for Cox model.

Abbreviations: PDC, proportion of days covered; MPR, medication possession ratio; Cl, confidence interval.

adherence tip sheet, copay relief card, option to enroll in My HeartWise ${ }^{\mathrm{TM}}$ Program) on patients' adherence to statin therapy, using atorvastatin as an example. Our findings indicate that both the control and intervention groups were quite similar (no inferential statistics were conducted) - both groups were from a relatively sick population exhibiting polypharmacy behavior (at least $85 \%$ of each group had a prior $\mathrm{CV}$ event). Most patients who had one, two, or three atorvastatin prescription refills during the study period obtained a 90-day supply (data not shown). In general, adherence and persistence for both the control and intervention groups were essentially the same, regardless of whether PDC or MPR was used as the outcome of interest. These unadjusted results were further validated by the findings of the logistic regression and Cox proportional hazards models, which did not indicate a significant difference among the cohorts of interest. As the control group's adherence was initially high, there was little room for improvement as a result of the intervention. In addition, the large number of continuing users and the level of treatment patients received at this particular cardiology practice group could explain the high adherence rate observed in this study, which in turn could partially explain the lack of a significant impact due to the intervention. The literature confirms that new users often exhibit lower adherence rates as compared with continuing users. ${ }^{13} \mathrm{In}$ a recent retrospective database analysis of treatment-naïve hyperlipidemia patients, $65 \%$ of patients were considered nonadherent $(\mathrm{PDC}=0.33){ }^{25}$
The overall cost of medication nonadherence to the health care system is staggering. Between one third and two thirds of medication-related hospital admissions are linked to poor adherence. ${ }^{9}$ Total cost estimates for nonadherence amount to at least US $\$ 300$ billion a year. ${ }^{26,27}$ Some general reasons for nonadherence include the patient being unconvinced of the need for therapy and/or its effectiveness, medication side effects, difficulty with regimen administration, forgetfulness, and out-of-pocket costs. As such, adherence interventions seek to directly address some, if not all, of these barriers. Evidence suggests that effective interventions combine education, motivation, support, reminders, and rewards, as a successful program must be delivered by a trusted source, be personalized to the patient's situation, reinforce medical need and expected outcomes, segment and target at-risk populations, and reinforce and reward initiation and maintenance..$^{28-30}$

Some interventions directed at patients with hypertension have resulted in an improvement in adherence or clinical outcomes. Two such studies of complex intervention programs, involving provision of care at the worksite, special pill containers, counseling, reminders, self-monitoring, support groups, and feedback and reinforcement, reported such positive effects. ${ }^{31,32}$ Another study tested a telephone-linked computer system for monitoring and counseling hypertension patients. When adjusted for age, sex, and baseline adherence, patients using the telephone-linked computer system demonstrated a greater improvement in medication adherence than did those 
receiving usual care. ${ }^{33}$ A previous systematic review of adherence interventions concluded that all interventions that were effective for long-term care were complex (including combinations of more convenient care, information, counseling, reminders, self-monitoring, reinforcement, family therapy, and other forms of additional supervision or attention); even so, the most effective ones did not lead to large improvements in adherence and treatment outcomes. ${ }^{33}$ Finally, the relative cost-effectiveness of adherence interventions should be taken into consideration when designing and implementing adherence-improving programs. ${ }^{34,35}$

There are several limitations that are worth noting here. The reader should be aware that both the patients and clinicians were not blinded to the study. The frequency with which discount cards were given to control patients was not tracked. However, because many of the patients were older than 65 years of age, the impact of discount cards was likely limited, as Medicare patients did not qualify to receive them. Although inferential statistics were not provided, the demographic profiles of the two cohorts were a bit disparate. The number of new users was small compared with the number of continuing users, an issue that should be taken into consideration when interpreting the findings (as a general guide, studies with a single intervention group and a control group need to include at least 60 participants per group if they are to have at least $80 \%$ power to detect an absolute difference of $25 \%$ in the proportion of patients judged to have adequate adherence). ${ }^{33}$ In addition, one should consider that perhaps 180 days of follow-up was not sufficient to identify a meaningful difference between the two cohorts. Regarding the data source, LRx does not track mail order prescriptions; as such, patients who may have been excluded due to lack of atorvastatin claims may have filled their prescriptions via this channel. In addition, administrative/pharmacy claims do not address whether or not the patient filled the prescription that was written for a particular medication, nor do they reveal the actual underlying barriers to adherence.

\section{Conclusion}

This study suggests that the impact of an integrated program including nurse counseling, copay relief cards, and a monthly newsletter did not significantly improve atorvastatin adherence relative to usual care in the studied patient population. Because adherence and persistence may be affected by numerous factors, including comorbidities and economic conditions, further evaluation of differences in adherence and persistence among the patients may be warranted.

\section{Disclosure}

This study was sponsored by Pfizer, Inc, NJG is a speaker for The Medicines Company, Medtronic, and Boston Scientific and is the medical director for SynvaCor. MDK and MRK are employees of IMS Health, which was a paid consultant to Pfizer in connection with the development of this article. AK, JM, LZL, and JV are employees of Pfizer, Inc, and own stock in Pfizer, Inc. PB and CD have no disclosures to declare at this time. The authors report no other conflicts of interest in this work.

\section{References}

1. HMG-CoA reductase inhibitors. In: Burnham TH, editor. Drug Facts and Comparisons. St Louis, MO: Facts and Comparisons, Inc; 2002: 536-542a.

2. Bavry AA, Mood GR, Kumbhani DJ, Borek PP, Askari AT, Bhatt DL. Long-term benefit of statin therapy initiated during hospitalization for an acute coronary syndrome: a systematic review of randomized trials. Am J Cardiovasc Drugs. 2007;7(2):135-141.

3. Allen Maycock CA, Muhlestein JB, Horne BD, et al; for the Intermountain Heart Collaborative Study. Statin therapy is associated with reduced mortality across all age groups of individuals with significant coronary disease, including very elderly patients. $\mathrm{J} \mathrm{Am} \mathrm{Coll}$ Cardiol. 2002;40(10):1777-1785.

4. Colhoun HM, Betteridge DJ, Durrington PN, et al; for the CARDS Investigators. Primary prevention of cardiovascular disease with atorvastatin in type 2 diabetes in the Collaborative Atorvastatin Diabetes Study (CARDS): multicentre randomised placebo-controlled trial. Lancet. 2004;364(9435):685-696.

5. Sever PS, Dahlöf B, Poulter NR, et al; for the ASCOT Investigators. Prevention of coronary and stroke events with atorvastatin in hypertensive patients who have average or lower-than-average cholesterol concentrations, in the Anglo-Scandinavian Cardiac Outcomes Trial-Lipid Lowering Arm (ASCOT-LLA): a multicentre randomised controlled trial. Drugs. 2004;64 Suppl 2:43-60.

6. Koren MJ, Hunninghake DB; for the ALLIANCE Investigators. Clinical outcomes in managed-care patients with coronary heart disease treated aggressively in lipid-lowering disease management clinics: the alliance study. J Am Coll Cardiol. 2004;44(9):1772-1779.

7. Waters DD, Schwartz GG, Olsson AG, et al; for the MIRACL Study Investigators. Effects of atorvastatin on stroke in patients with unstable angina or non-Q-wave myocardial infarction: a Myocardial Ischemia Reduction with Aggressive Cholesterol Lowering (MIRACL) substudy. Circulation. 2002;106(13):1690-1695.

8. LaRosa JC, Grundy SM, Waters DD, et al; for the Treating to New Targets (TNT) Investigators. Intensive lipid lowering with atorvastatin in patients with stable coronary disease. $N$ Engl J Med. 2005;352(14): $1425-1435$.

9. Osterberg L, Blaschke T. Adherence to medication. $N$ Engl J Med. 2005;353(5):487-497.

10. Sabaté E. Adherence to Long-Term Therapies: Evidence for Action. Geneva, Switzerland: World Health Organization; 2003.

11. Goodman A. Cost-sharing strategies decrease adherence to statin therapy. American Health and Drug Benefits. 2009;2(1):28.

12. Ockene IS, Hayman LL, Pasternak RC, Schron E, Dunbar-Jacob J. Task force \#4 - adherence issues and behavior changes: achieving a long-term solution. 33rd Bethesda Conference. J Am Coll Cardiol. 2002;40(4):630-640.

13. Jackevicius CA, Mamdani M, Tu JV. Adherence with statin therapy in elderly patients with and without acute coronary syndromes. JAMA. 2002;288(4):462-467. 
14. Berg JS, Dischler J, Wagner DJ, Raia JJ, Palmer-Shevlin N. Medication compliance: a healthcare problem. Ann Pharmacother. 1993; 27(Supp1 9):S1-S24.

15. National Pharmaceutical Council. Noncompliance with Medication Regimens: An Economic Tragedy. Emerging Issues in Pharmaceutical Cost Containing. Washington, DC: National Pharmaceutical Council; 1992:1-16.

16. Benner JS, Glynn RJ, Mogun H, Neumann PJ, Weinstein MC, Avorn J. Long-term persistence in use of statin therapy in elderly patients. JAMA 2002;288(4):455-461.

17. Ogedegbe G, Chaplin W, Schoenthaler A, et al. A practice-based trial of motivational interviewing and adherence in hypertensive African Americans. Am J Hypertens. 2008;21(10):1137-1143.

18. World Health Organization. Adherence to long-term. 24. therapies Geneva, Switzerland; 2003; ISBN 924 1545992. Available from: http://www.gammagard.com/pdf/1-nurse-intro-to-pi.pdf. Accessed on July 1, 2013

19. Stewart MA. Effective physician-patient communication and health outcomes: a review. CMAJ. 1995;152(9):1423-1433.

20. Roter DL, Hall JA, Merisca R, Nordstrom B, Cretin D, Svarstad B. Effectiveness of interventions to improve patient compliance: a metaanalysis. Med Care. 1998;36(8):1138-1161.

21. Rogers CR. Carl Rogers on the development of the person-centered approach. Person-Centered Review. 1986;1(3):257-259.

22. Emmons KM, Rollnick S. Motivational interviewing in health care settings. Opportunities and limitations. Am J Prev Med. 2001;20(1): 68-74.

23. Ruppar TM. Randomized pilot study of a behavioral feedback intervention to improve medication adherence in older adults with hypertension. J Cardiovasc Nurs. 2010;25(6):470-479.

24. Chase J. IMC $C^{2}$ Health and Wellness. New York, NY: MM\&M/ Haymarket Media, Inc; 2013. Available from: http://media. mmm-online.com/documents/14/imc2_3483.pdf. Accessed June 18, 2013.

25. Wiegand P, McCombs JS, Wang JJ. Factors of hyperlipidemia medication adherence in a nationwide health plan. Am J Manag Care. 2012;18(4):193-199.
26. New England Healthcare Institute. Thinking Outside the Pillbox: A System-wide Approach to Improving Patient Medication Adherence for Chronic Disease. Cambridge, MA: New England Healthcare Institute; 2009.

27. Balkrishnan R. The importance of medication adherence in improving chronic-disease related outcomes: what we know and what we need to further know. Med Care. 2005;43(6):517-520.

28. Haynes RB, McKibbon KA, Kanani R. Systematic review of randomised trials of interventions to assist patients to follow prescriptions for medications. Lancet. 1996;348(9024):383-386.

29. Newell SA, Bowman JA, Cockburn JD. A critical review of interventions to increase compliance with medication-taking, obtaining medication refills, and appointment-keeping in the treatment of cardiovascular disease. Prev Med. 1999;29(6 Pt 1):535-548.

30. McDonald HP, Garg AX, Haynes RB. Interventions to enhance patient adherence to medication prescriptions: scientific review. JAMA. 2002;288(22):2868-2879.

31. Haynes RB, Sackett DL, Gibson ES, et al. Improvement of medication compliance in uncontrolled hypertension. Lancet. 1976;1(7972): $1265-1268$

32. Logan AG, Milne BJ, Achber C, Campbell WP, Haynes RB. Work-site treatment of hypertension by specially trained nurses. A controlled trial. Lancet. 1979;2(8153):1175-1178.

33. Friedman RH, Kazis LE, Jette A, et al. A telecommunications system for monitoring and counseling patients with hypertension. Impact on medication adherence and blood pressure control. Am J Hypertens. 1996;9(4 Pt 1):285-292.

34. Chapman RH, Kowal SL, Cherry SB, Ferrufino CP, Roberts CS, Chen L. The modeled lifetime cost-effectiveness of published adherence-improving interventions for antihypertensive and lipidlowering medications. Value Health. 2010;13(6):685-694.

35. Chapman RH, Ferrufino CP, Kowal SL, Classi P, Roberts CS. The cost and effectiveness of adherence-improving interventions for antihypertensive and lipid-lowering drugs*. Int J Clin Pract. 2010;64(2) $169-181$.
International Journal of General Medicine

\section{Publish your work in this journal}

The International Journal of General Medicine is an international, peer-reviewed open-access journal that focuses on general and internal medicine, pathogenesis, epidemiology, diagnosis, monitoring and treatment protocols. The journal is characterized by the rapid reporting of reviews, original research and clinical studies across all disease areas.

\section{Dovepress}

A key focus is the elucidation of disease processes and management protocols resulting in improved outcomes for the patient.The manuscript management system is completely online and includes a very quick and fair peer-review system. Visit http://www.dovepress.com/ testimonials.php to read real quotes from published authors. 